Article

\title{
First Principles Density Functional Theory Prediction of the Crystal Structure and the Elastic Properties of $\mathrm{Mo}_{2} \mathrm{ZrB}_{2}$ and $\mathrm{Mo}_{2} \mathrm{HfB}_{2}$
}

\author{
Rachid Stefan Touzani * and Manja Krüger \\ Institute of Materials and Joining Technology, Otto-von-Guericke University Magdeburg, P.O. Box 4120, \\ D-39016 Magdeburg, Germany; manja.krueger@ovgu.de \\ * Correspondence: rachid.touzani@ovgu.de
}

Received: 11 September 2020; Accepted: 22 September 2020; Published: 24 September 2020

\begin{abstract}
The Molybdenum rich ternary alloys Mo-M-B ( $\mathrm{M}=\mathrm{Zr}$, Hf) contain, next to the Mo solid solution (bcc Mo with small amounts of $\mathrm{Zr}$ or $\mathrm{Hf}$ as substitutional atoms), the binary borides $\mathrm{Mo}_{2} \mathrm{~B}$, $\mathrm{MB}$ and $\mathrm{MB}_{2}$. Recently, it was found that there is also ternary $\mathrm{Mo}_{2} \mathrm{MB}_{2}$, but the crystal structure and further properties are currently unknown. Density functional theory (DFT) calculations were used not only to predict the crystal structure of the $\mathrm{Mo}_{2} \mathrm{MB}_{2}$ phases, but also to estimate the isotropic and anisotropic elastic properties like bulk, shear and Young's modulus, as well as the Vickers hardness of these new borides. Several known crystal structures that fulfill the criterion of the chemical composition were investigated, and the $\mathrm{AlMn}_{2} \mathrm{~B}_{2}$ type structure seems to be the most stable crystal structure for $\mathrm{Mo}_{2} \mathrm{HfB}_{2}$ and $\mathrm{Mo}_{2} \mathrm{ZrB}_{2}$ as there are no signs of electronic or dynamic instability. Regarding the elastic properties, it was found that $\mathrm{Mo}_{2} \mathrm{HfB}_{2}$ shows higher elastic moduli and is less elastically anisotropic than $\mathrm{Mo}_{2} \mathrm{ZrB}_{2}$.
\end{abstract}

Keywords: density functional theory; elastic properties; crystal structure; borides; intermetallics; molybdenum based alloys

\section{Introduction}

There is a significant demand for new high-performance materials for technically challenging applications, e.g., in the metal processing industry, or in the energy generation and the aviation sectors. It is well-accepted that the materials capability affects the performance of machines, like turbines [1]. State-of-the-art materials for heavily stressed structural components are single-crystalline nickel-based superalloys. However, beyond $\sim 1100{ }^{\circ} \mathrm{C}$, the strength of these materials drops significantly and, thus, they become unusable for structural components.

The most challenging goal is to develop new high-temperature materials that provide balanced properties in a wide temperature range, i.e., sufficient fracture toughness at low and ambient temperatures, as well as creep strength and appropriate oxidation resistance at ultra-high temperatures. This target could be met by tailored refractory metal alloys, e.g., those based on molybdenum [2-5]. Mostly, the alloying strategy is due to the formation of temperature and oxidation-resistant intermetallic phases in a molybdenum solid solution matrix, like different silicides [6,7]. Recently, systems that incorporate borides as strengthening phases were described in terms of their microstructural evolution and mechanical properties, namely the ternary systems Mo-Hf-B and Mo-Zr-B [8-10]. It could be shown that this class of materials is very attractive in terms of a promising combination of high fracture toughness and outstanding creep resistance. The borides especially, e.g., $\mathrm{ZrB}, \mathrm{HfB}$ or $\mathrm{Mo}_{2} \mathrm{~B}$, and the respective ternary borides that form in Mo-rich alloys, provide excellent creep resistance. Since boride phases, as well as the molybdenum solid solution phase, show a loss of environmental resistance at 
intermediate temperatures, a coating strategy based on Si-N and Si-O ceramic phases was already developed [11].

However, there is a lack of data on the properties of the ternary phases, especially their thermodynamic stability within the ternary systems Mo-Hf-B and Mo-Zr-B. The latest versions of the respective phase diagrams were published by Rogl, which do not contain the Mo-rich ternary intermetallic phases $[12,13]$. In our preliminary work so far, we found undescribed ternary phases, which were provisionally named $\mathrm{Mo}_{2} \mathrm{HfB}_{\mathrm{x}}$ and $\mathrm{Mo}_{2} \mathrm{ZrB}_{\mathrm{x}}$ in previous publications $[9,10]$. More precise information on the exact chemical composition of the phases was derived from Atom Probe Tomography (APT) measurements $[14,15]$. These results give evidence on the type of phases to be $\mathrm{Mo}_{2} \mathrm{MB}_{2}(\mathrm{M}=\mathrm{Zr}$, Hf), but the crystal structure and stability of the phases is still unclear.

The prediction of the crystal structure of new materials or of known crystals at extreme conditions is an ongoing research topic. Diverse methods exist, e.g., Random Sampling [16], Simulated Annealing [17] and Evolutionary Algorithms [18], often in combination with Density Functional Theory (DFT) calculations. One drawback of using these methods, however, can be the high demand of calculation power and/or time. To overcome these drawbacks, a different approach was used to predict the crystal structure of $\mathrm{Mo}_{2} \mathrm{MB}_{2}(\mathrm{M}=\mathrm{Zr}, \mathrm{Hf})$ by simply using known crystals structures of intermetallics with the 2-1-2 or 3-2 chemical composition within our DFT calculations.

\section{Materials and Methods}

Based on the measured chemical composition 2-1-2 for Mo, M (M = Zr, Hf) and B, respectively, for the new compounds [14,15], we took 50 crystal structures of already known 2-1-2 and 3-2 intermetallics that fulfill the above-mentioned criterion of composition. Of those 50 types of crystal structures, the nine that showed the lowest total energy were those of the $\mathrm{AlMn}_{2} \mathrm{~B}_{2}$-type [19], the $\mathrm{Mo}_{2} \mathrm{FeB}_{2}$-type [20], the $\mathrm{Nb}_{2} \mathrm{OsB}_{2}$-type (a superstructure variant of the $\mathrm{Mo}_{2} \mathrm{FeB}_{2}$-type) [21], the $\mathrm{U}_{2} \mathrm{Pt}_{2} \mathrm{Sn}$-type [22] (also a superstructure variant of the $\mathrm{Mo}_{2} \mathrm{FeB}_{2}$-type, but no boride is currently known), the $\mathrm{CeAl}_{2} \mathrm{Ga}_{2}$-type (e.g., the known boride $\mathrm{DyCo}_{2} \mathrm{~B}_{2}$ [23]), the $\beta$ - $\mathrm{Cr}_{2} \mathrm{IrB}_{2}$-type [24], the $\mathrm{Mo}_{2} \mathrm{IrB}_{2}$-type [25], the $\mathrm{HoNi}_{2} \mathrm{~B}_{2}$-type [26] and the $\mathrm{W}_{2} \mathrm{CoB}_{2}$-type [27]. First-principles calculation were carried out with Quickstep [28], as implemented in the CP2K version 5.1 program package, for a first structural relaxation and a quick estimation of the total energy [29]. Using the Gaussian plane wave method (GPW) [30], for Mo, Zr, Hf and B, the DZVP-MOLOPT-SR-GTH basis was set [31] and GTH-pseudopotentials were chosen [32-34]. Cell shape and volume variations were allowed during the structural optimization until a total energy self-consistency of $10^{-8}$ Ha and until the self-consistency for the forces and maximum geometry change of $10^{-6} \mathrm{Ha} / \mathrm{Bohr}$ and $10^{-6} \mathrm{Bohr}$, respectively, were achieved. The energy cut-off for the plane waves on the grid was $600 \mathrm{Ha}$, and the k-meshes were sampled via the Monkhorst-Pack algorithm [35]. Exchange and correlation in this density functional theory (DFT)-based method were treated with the generalized gradient approximation (GGA) functional as parameters by Perdew, Burke and Ernzerhof (PBE-GGA) [36]. Additionally, the PHONOPY program [37] was used to check for the dynamically most stable structure, similar to an approach made in Ref. [38].

The Density-Of-States calculation was done on the most stable energy ground-state structure using the tight-binding, linear muffin-tin orbitals with the atomic spheres approximation (TB-LMTO-ASA) [39,40] as implemented in the TB-LMTO 4.7 program. The Fermi level $\left(E_{F}\right)$ was set to $0 \mathrm{eV}$. The MonkhorstPack algorithm generated k-mesh was $27 \times 27 \times 27$. Exchange and correlation were treated with the PW91-GGA functional by Perdew et al. [41]. The bonding analysis was done by calculation of the crystal orbital Hamilton population (COHP) [42] and its integrals (ICOHP). The ICOHP can be seen as a semi-quantitative bonding energy that measures covalent contributions in solids.

For the calculation of the elastic properties, a further structure optimization of the most stable crystal structure was carried out with Quantum ESPRESSO [43,44] using PAW pseudopotentials [45] from the PSLibrary version 1.0.0 [46]. The kinetic energy cut-off of the plane waves was set to $100 \mathrm{Ry}$, while the cut-off for the charge of density and potential was set to $400 \mathrm{Ry}$. The structural relaxation stopped until a total energy convergence of $10^{-6} \mathrm{Ry}$ and a force convergence of $10^{-5} \mathrm{Ry} / \mathrm{Bohr}$ were 
reached. The Marzari-Vanderbilt cold smearing [47] and a Gaussian spreading of 0.01 Ry were chosen to account for the Brillouin-zone integration in metals. The k-mesh was divided by $20 \times 4 \times 20$ using the aforementioned Monkhorst-Pack algorithm. Exchange and correlation in this density functional theory (DFT) based method were again treated with PBE-GGA. The elastic properties were determined with thermo_pw [48], a Fortran program using Quantum ESPRESSO routines as the underlying engine. In order to get the Voight-Reuss-Hill [49-51] approximated bulk, shear and Young's modulus, the standard algorithm and frozen ions were used. To calculate the Vickers hardness, Tian et al.'s formula [52] was used. The formulas for the anisotropic bulk and Young's modulus were taken from Ref. [53], while the formula for the anisotropic shear modulus is based from the formula given in [54]. Because of the usage of directional cosines of the elastic constants along the $x-, y_{-}, z_{-}, x y-, x z-$ and $y z$-directions (see Ref. [53]), the elastic moduli along the crystallographic $\{111\}$ direction is the average of the $\{111\}$ directions within the $a b-c-, a c-b$ - and $b c-a$-plane, which is spanned by the vectors along $\{110\}$ $\&\{001\},\{101\} \&\{010\}$ and $\{011\} \&\{100\}$, respectively.

The elastic anisotropy was determined in two ways: First, we calculated the Universal Elastic Anisotropy Index using the Voigt and Reuss bulk and shear moduli [55]. Second, as there are maxima and minima of the anisotropic elastic moduli, one can make another estimation of the anisotropy for the bulk, shear and Young's modulus as well as the Vickers hardness using the following Formula (1) [56]:

$$
E M A I=\frac{E M_{\max }}{E M_{\min }}
$$

$E M A I$ : Elastic modulus anisotropy index; $E M_{\max }$ : Maximum of the elastic modulus; $E M_{\min }$ : Minimum of the elastic modulus.

If $E M A I=0$, then the elastic modulus is isotropic; a higher $E M A I$ should display a more anisotropic elastic modulus.

\section{Results and Discussion}

\subsection{Crystal, Electronic and Phonon Structure}

To predict the crystal structure of a compound, the total energy per formula unit is the main decision criterion. Here, nine crystal structure candidates for $\mathrm{Mo}_{2} \mathrm{MB}_{2}(\mathrm{M}=\mathrm{Zr}, \mathrm{Hf})$ and their total energy difference to the energetically most stable structure type will be presented: the AlMn ${ }_{2} \mathrm{~B}_{2}$-type [19], the $\mathrm{Mo}_{2} \mathrm{FeB}_{2}$-type [20], the $\mathrm{Nb}_{2} \mathrm{OsB}_{2}$-type (a superstructure variant of the $\mathrm{Mo}_{2} \mathrm{FeB}_{2}$-type) [21], the $\mathrm{U}_{2} \mathrm{Pt}_{2} \mathrm{Sn}$-type [22] (also a superstructure variant of the $\mathrm{Mo}_{2} \mathrm{FeB}_{2}$-type, but no boride is currently known), the $\mathrm{CeAl}_{2} \mathrm{Ga}_{2}$-type (e.g., the known boride $\mathrm{DyCo}_{2} \mathrm{~B}_{2}$ [23]), the $\beta$ - $\mathrm{Cr}_{2} \mathrm{IrB}_{2}$-type [24], the $\mathrm{Mo}_{2} \mathrm{IrB}_{2}$-type [25], the $\mathrm{HoNi}_{2} \mathrm{~B}_{2}$-type [26] and the $\mathrm{W}_{2} \mathrm{CoB}_{2}$-type [27].

Their calculated energy differences are shown in Figure 1. It is obvious that the $\mathrm{AlMn}_{2} \mathrm{~B}_{2}$-type structure (see inlay of Figure 1) is the most stable one of all investigated structures for $\mathrm{Mo}_{2} \mathrm{ZrB}_{2}$ and $\mathrm{Mo}_{2} \mathrm{HfB}_{2}$. The AlMn $\mathrm{B}_{2}$-type is a structure variant within the orthorhombic spacegroup Cmmm. The $\mathrm{Mo}_{2} \mathrm{FeB}_{2}$-type structure for $\mathrm{Mo}_{2} \mathrm{ZrB}_{2}\left(\mathrm{Mo}_{2} \mathrm{HfB}_{2}\right)$ is less stable with an energy difference of $+23 \mathrm{~kJ} / \mathrm{mol}(+15 \mathrm{~kJ} / \mathrm{mol})$. The $\mathrm{Nb}_{2} \mathrm{OsB}_{2}$ and $\mathrm{U}_{2} \mathrm{Pt}_{2} \mathrm{Sn}$ types are structurally unstable as they both changed towards the $\mathrm{Mo}_{2} \mathrm{FeB}_{2}$-type during the cell optimization. The CeRu $\mathrm{Al}_{2}$-type, $\beta$ - $\mathrm{Cr}_{2} \mathrm{IrB}_{2}$-type, $\mathrm{Mo}_{2} \mathrm{IrB}_{2}$-type, $\mathrm{HoNi}_{2} \mathrm{~B}_{2}$-type and $\mathrm{W}_{2} \mathrm{CoB}_{2}$-type are even more unstable with energy differences of $+24 \mathrm{~kJ} / \mathrm{mol}(+55 \mathrm{~kJ} / \mathrm{mol}),+42 \mathrm{~kJ} / \mathrm{mol}(+54 \mathrm{~kJ} / \mathrm{mol}),+51 \mathrm{~kJ} / \mathrm{mol}(+60 \mathrm{~kJ} / \mathrm{mol}),+109 \mathrm{~kJ} / \mathrm{mol}(+132 \mathrm{~kJ} / \mathrm{mol})$ and $+134 \mathrm{~kJ} / \mathrm{mol}(+129 \mathrm{~kJ} / \mathrm{mol})$, respectively. 


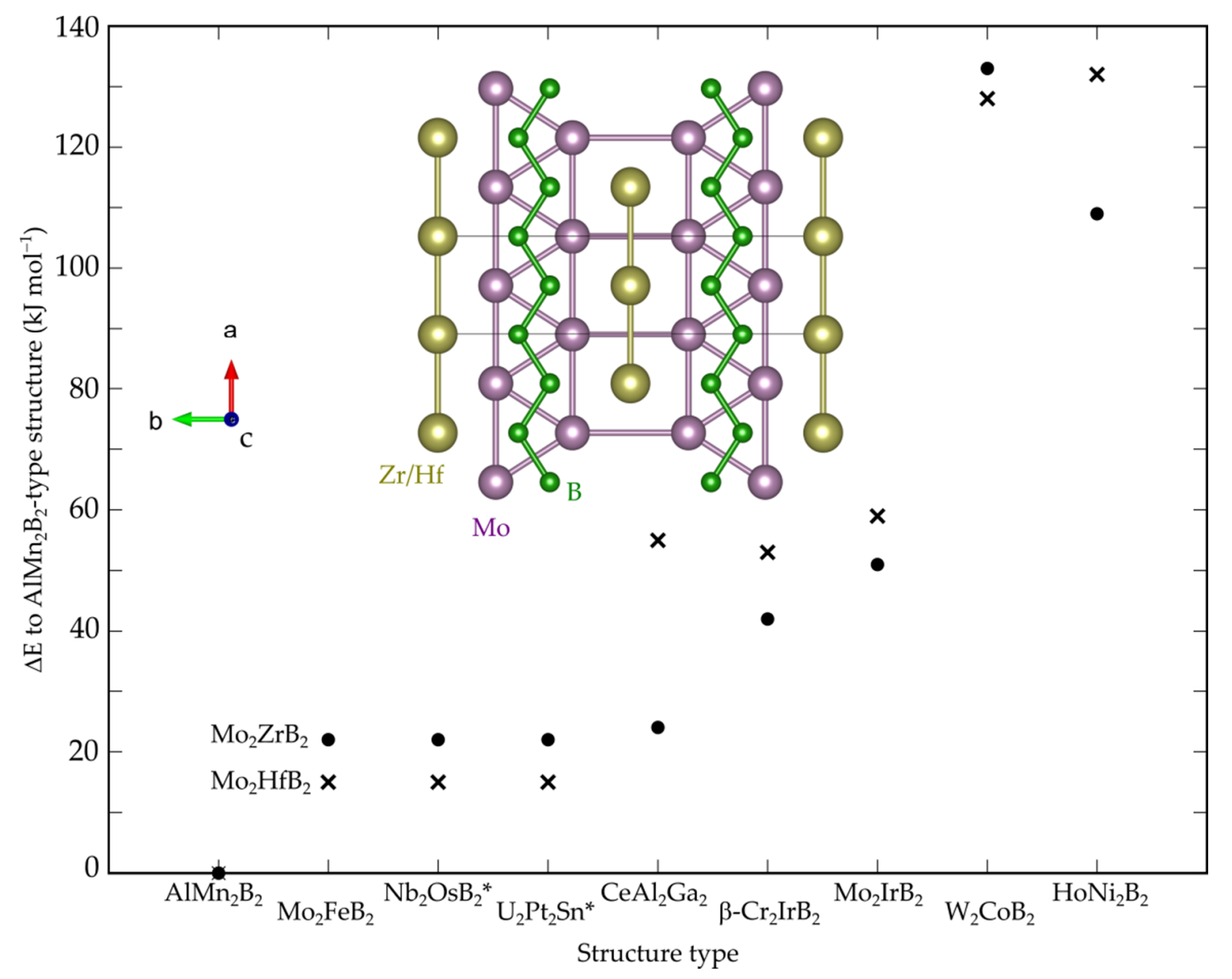

Figure 1. The calculated energy differences of the phases $\mathrm{Mo}_{2} \mathrm{ZrB}_{2}$ and $\mathrm{Mo}_{2} \mathrm{HfB}_{2}$ per formula unit with the different types of crystal structures. *: Unstable crystal structures, which turn to the $\mathrm{Mo}_{2} \mathrm{FeB}_{2}$ type during the structural relaxation.

To check if the AlMn ${ }_{2} B_{2}$ type is electronically and dynamically stable, we also calculated the electronic Density-Of-States (DOS, Figure 2) and the Phonon-Density-of-States (PDS, Figure 3). In Figure 2 (left), the DOS of $\mathrm{Mo}_{2} \mathrm{ZrB}_{2}$ shows no signs of electronic instabilities as the Fermi level lies in the vicinity of a local DOS minimum. However, the Fermi level of $\mathrm{Mo}_{2} \mathrm{HfB}_{2}$ (see Figure 2, right) lies close to a small maximum of the DOS, which might indicate the formation of boron vacancies, but is no serious sign of an instability of the crystal structure. Because of the non-vanishing DOS at the Fermi level, $\mathrm{Mo}_{2} \mathrm{ZrB}_{2}$ and $\mathrm{Mo}_{2} \mathrm{HfB}_{2}$ should be metals.

The PDS of $\mathrm{Mo}_{2} \mathrm{ZrB}_{2}$ with the $\mathrm{AlMn}_{2} \mathrm{~B}_{2}$ type structure in Figure 3 (left) contains no occupied imaginary frequencies and, hence, no dynamic instability is found. The same is valid for the PDS of $\mathrm{Mo}_{2} \mathrm{HfB}_{2}$ (Figure 3, right).

In terms of geometry, the lattice parameters of $\mathrm{Mo}_{2} \mathrm{ZrB}_{2}$ and of $\mathrm{Mo}_{2} \mathrm{HfB}_{2}$ after the cell optimization with CP2k are presented in Table 1. After a further structural optimization for the subsequent calculation of the elastic properties (see Section 3.2) with Quantum ESPRESSO, the lattice parameters of $\mathrm{Mo}_{2} \mathrm{ZrB}_{2}$ and $\mathrm{Mo}_{2} \mathrm{HfB}_{2}$ do not change much (see also Table 1 for the respective volumes).

Because of the similar atomic radius in crystals of $\mathrm{Zr}$ and $\mathrm{Hf}$ (both $155 \mathrm{pm}$ according to Slater [57]), the lattice parameters $a$ and $c$ of $\mathrm{Mo}_{2} \mathrm{ZrB}_{2}$ and $\mathrm{Mo}_{2} \mathrm{HfB}_{2}$ differ by less than $1 \%$, while the difference for the lattice parameter $b$ is about $2 \%$. The difference might come from the slightly different chemical behavior of $\mathrm{Zr}$ and $\mathrm{Hf}$. 


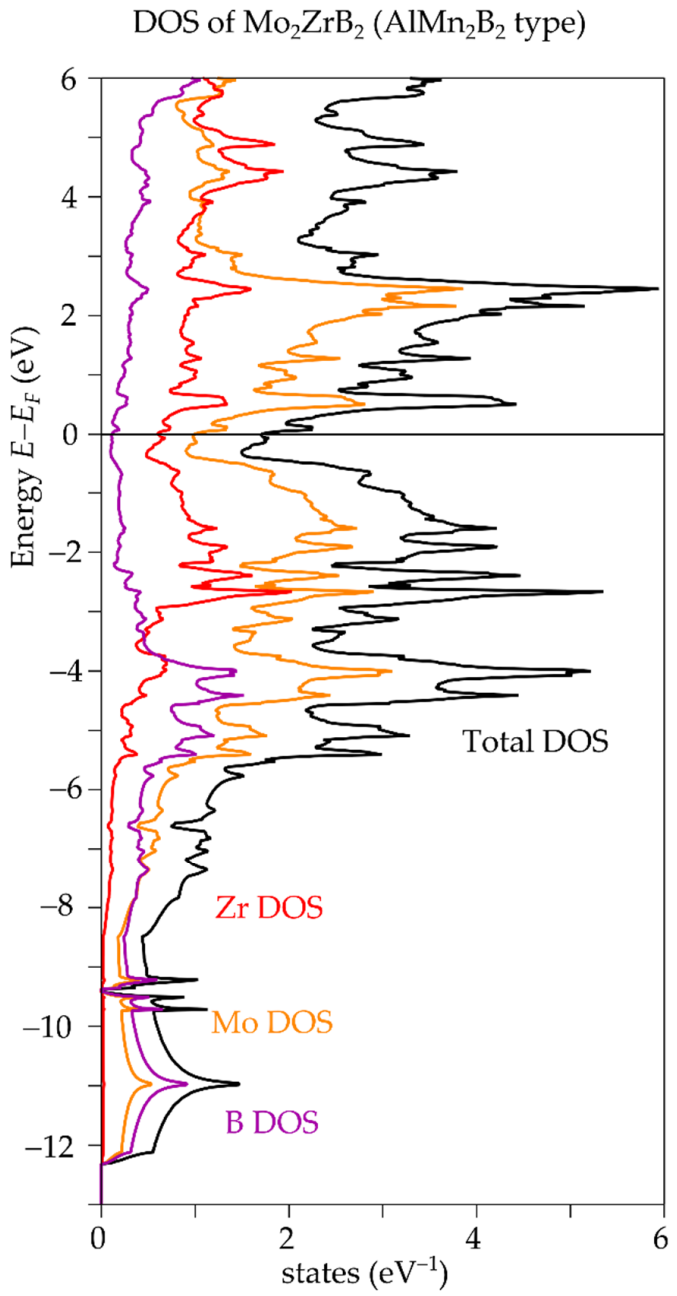

DOS of $\mathrm{Mo}_{2} \mathrm{HfB}_{2}\left(\mathrm{AlMn}_{2} \mathrm{~B}_{2}\right.$ type $)$

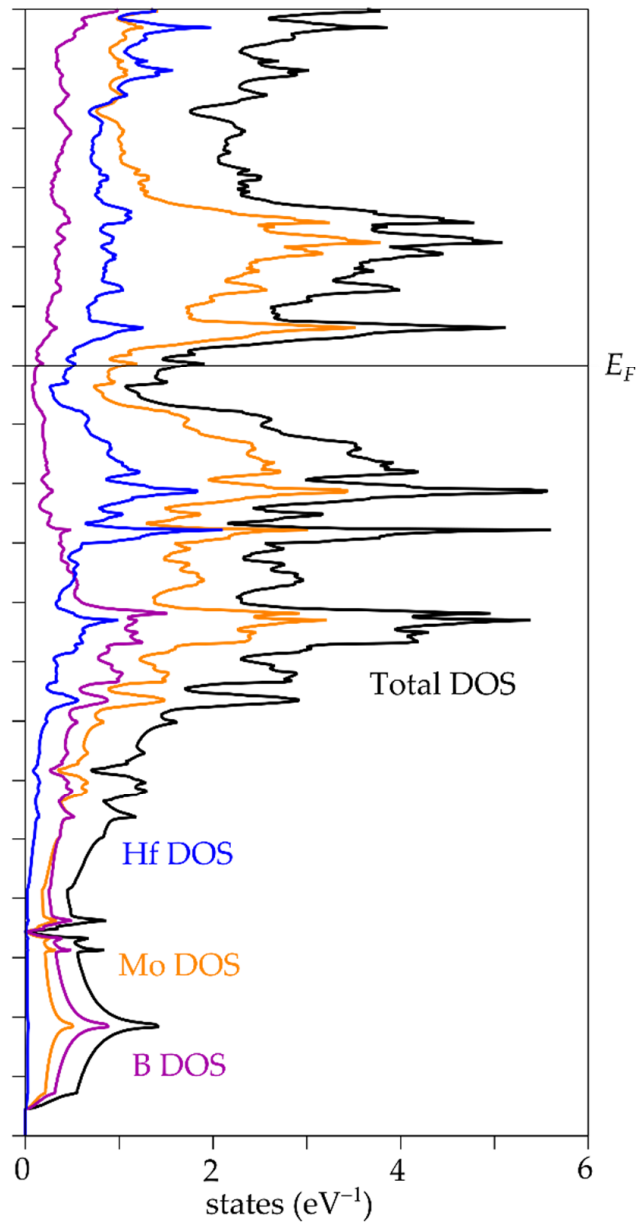

Figure 2. Electronic density of states (DOS) of $\mathrm{Mo}_{2} \mathrm{ZrB}_{2}$ (left) and Mo2HfB2 (right) both with $\mathrm{AlMn}_{2} \mathrm{~B}_{2}$-type structure.

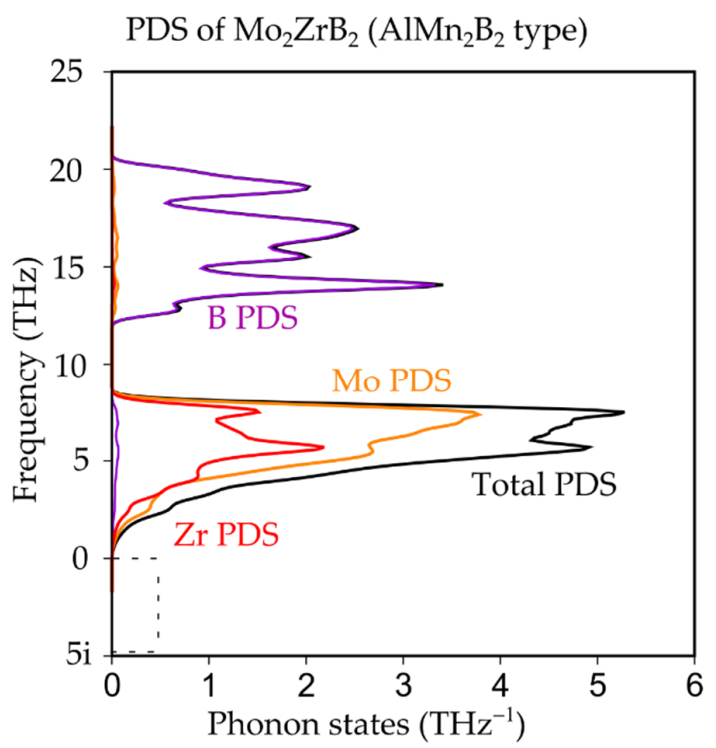

PDS of $\mathrm{Mo}_{2} \mathrm{HfB}_{2}\left(\mathrm{AlMn}_{2} \mathrm{~B}_{2}\right.$ type $)$

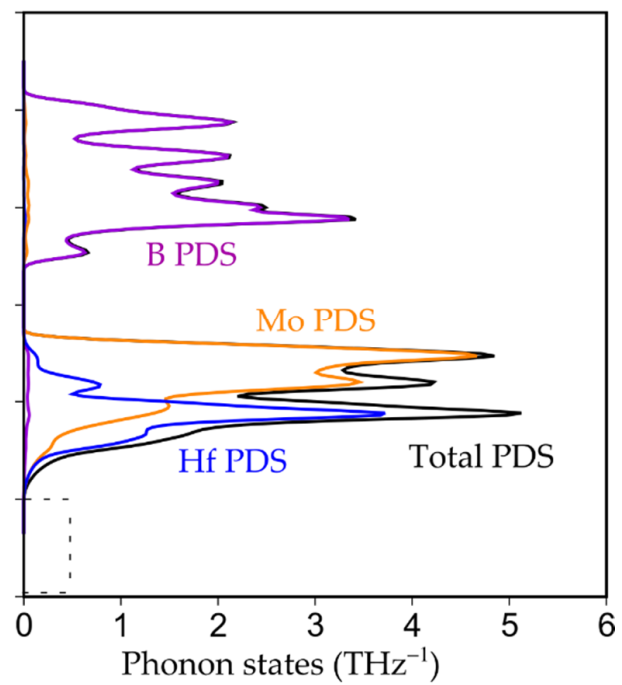

Figure 3. Phonon-Density-of-States (PDS) of $\mathrm{Mo}_{2} \mathrm{ZrB}_{2}$ (left) and $\mathrm{Mo}_{2} \mathrm{HfB}_{2}$ (right) both with $\mathrm{AlMn}_{2} \mathrm{~B}_{2}-$ type structure. The dashed boxes show that there are no imaginary phonon frequencies for $\mathrm{Mo}_{2} \mathrm{ZrB}_{2}$ and $\mathrm{Mo}_{2} \mathrm{HfB}_{2}$. 
Table 1. Lattice parameters $a, b, c$ and volumes of $\mathrm{Mo}_{2} \mathrm{ZrB}_{2}$ and $\mathrm{Mo}_{2} \mathrm{HfB}_{2}$ as calculated with $\mathrm{CP} 2 \mathrm{k}$ (Quantum ESPRESSO).

\begin{tabular}{ccccc}
\hline Compound & $\boldsymbol{a}(\AA)$ & $\boldsymbol{b}(\AA)$ & $\boldsymbol{c}(\AA)$ & $\mathbf{V}\left(\AA^{3}\right)$ \\
\hline $\mathrm{Mo}_{2} \mathrm{ZrB}_{2}$ & $3.145(3.146)$ & $12.59(12.60)$ & $3.208(3.208)$ & $127.1(127.2)$ \\
$\mathrm{Mo}_{2} \mathrm{HfB}_{2}$ & $3.143(3.141)$ & $12.33(12.35)$ & $3.213(3.212)$ & $124.6(124.6)$ \\
\hline
\end{tabular}

In conclusion, the $\mathrm{AlMn}_{2} \mathrm{~B}_{2}$-type is found to be the most energetic, electronic and dynamic stable structure for both $\mathrm{Mo}_{2} \mathrm{ZrB}_{2}$ and $\mathrm{Mo}_{2} \mathrm{HfB}_{2}$.

\subsection{Elastic Properties}

\subsubsection{Isotropic Elastic Properties}

In this section, the isotropic bulk, shear and Young's modulus along with the Vickers hardness of $\mathrm{Mo}_{2} \mathrm{ZrB}_{2}$ and $\mathrm{Mo}_{2} \mathrm{HfB}_{2}$ will be discussed (see also Table 2).

Table 2. Isotropic bulk modulus $B$, shear modulus $G$, Young's modulus $Y$, Vickers hardness $H^{V}$ and the Universal Elastic Anisotropy Index $A^{U}$ of $\mathrm{Mo}_{2} \mathrm{ZrB}_{2}$ and $\mathrm{Mo}_{2} \mathrm{HfB}_{2}$.

\begin{tabular}{cccccc}
\hline Compound & $\boldsymbol{B}(\mathrm{GPa})$ & $\boldsymbol{G}(\mathrm{GPa})$ & $\boldsymbol{Y}(\mathrm{GPa})$ & $\boldsymbol{H}^{V}(\mathrm{GPa})$ & $\boldsymbol{A}^{U}(\mathbf{)}$ \\
\hline $\mathrm{Mo}_{2} \mathrm{ZrB}_{2}$ & 241.19 & 148.34 & 369.30 & 18.24 & 0.03 \\
$\mathrm{Mo}_{2} \mathrm{HfB}_{2}$ & 250.31 & 158.73 & 393.11 & 19.81 & 0.02 \\
\hline
\end{tabular}

It is clear that all the isotropic elastic moduli and the Vickers hardness of $\mathrm{Mo}_{2} \mathrm{HfB}_{2}$ are higher than those of $\mathrm{Mo}_{2} \mathrm{ZrB}_{2}$.

The Universal Elastic Anisotropy Index [52] of $\mathrm{Mo}_{2} \mathrm{ZrB}_{2}$ and $\mathrm{Mo}_{2} \mathrm{HfB}_{2}$ was also calculated and while it is slightly larger for $\mathrm{Mo}_{2} \mathrm{ZrB}_{2}$ than for $\mathrm{Mo}_{2} \mathrm{HfB}_{2}$, it is very small for both compounds. A deeper analysis of the anisotropic elastic properties is presented in the next subsection.

\subsubsection{Anisotropic Elastic Properties}

In this section, the anisotropic elastic moduli bulk, shear and Young's modulus, along with the Vickers hardness of $\mathrm{Mo}_{2} \mathrm{ZrB}_{2}$ and $\mathrm{Mo}_{2} \mathrm{HfB}_{2}$, will be discussed. The discussion starts with the anisotropic bulk modulus shown in Figure 4.

The minimum of the anisotropic bulk modulus of $\mathrm{Mo}_{2} \mathrm{ZrB}_{2}$ and $\mathrm{Mo}_{2} \mathrm{HfB}_{2}$ is $227.14 \mathrm{GPa}$ and $239.41 \mathrm{GPa}$, respectively, and can be found along the $\{010\}$ direction. Along the $\{100\}$, the bulk modulus of $\mathrm{Mo}_{2} \mathrm{ZrB}_{2}$ and $\mathrm{Mo}_{2} \mathrm{HfB}_{2}$ is $257.32 \mathrm{GPa}$ and $263.00 \mathrm{GPa}$, respectively, which is the maximum.

Taking into account the maximum and minimum of the elastic moduli of $\mathrm{Mo}_{2} \mathrm{ZrB}_{2}$ and $\mathrm{Mo}_{2} \mathrm{HfB}_{2}$, one can make an assumption of the anisotropy (see Table 3): For the bulk modulus, the anisotropy is 0.13 and 0.10 for $\mathrm{Mo}_{2} \mathrm{ZrB}_{2}$ and $\mathrm{Mo}_{2} \mathrm{HfB}_{2}$, respectively.

Table 3. Anisotropy of the bulk, shear and Young's modulus as well as the Vickers hardness of $\mathrm{Mo}_{2} \mathrm{ZrB}_{2}$ and $\mathrm{Mo}_{2} \mathrm{HfB}_{2}$.

\begin{tabular}{cccccc}
\hline Compound & $\begin{array}{c}\text { B Anisotropy } \\
\text { Index ( ) }\end{array}$ & $\begin{array}{c}G \text { Anisotropy } \\
\text { Index ( ) }\end{array}$ & $\begin{array}{c}Y \text { Anisotropy } \\
\text { Index ( ) }\end{array}$ & $\begin{array}{c}H^{V} \text { Anisotropy } \\
\text { Index ( ) }\end{array}$ & $\begin{array}{c}B \text { and G Averaged } \\
\text { Anisotropy Index () }\end{array}$ \\
\hline $\mathrm{Mo}_{2} \mathrm{ZrB}_{2}$ & 0.13 & 0.10 & 0.21 & 0.21 & 0.12 \\
$\mathrm{Mo}_{2} \mathrm{HfB}_{2}$ & 0.10 & 0.08 & 0.18 & 0.18 & 0.09 \\
\hline
\end{tabular}




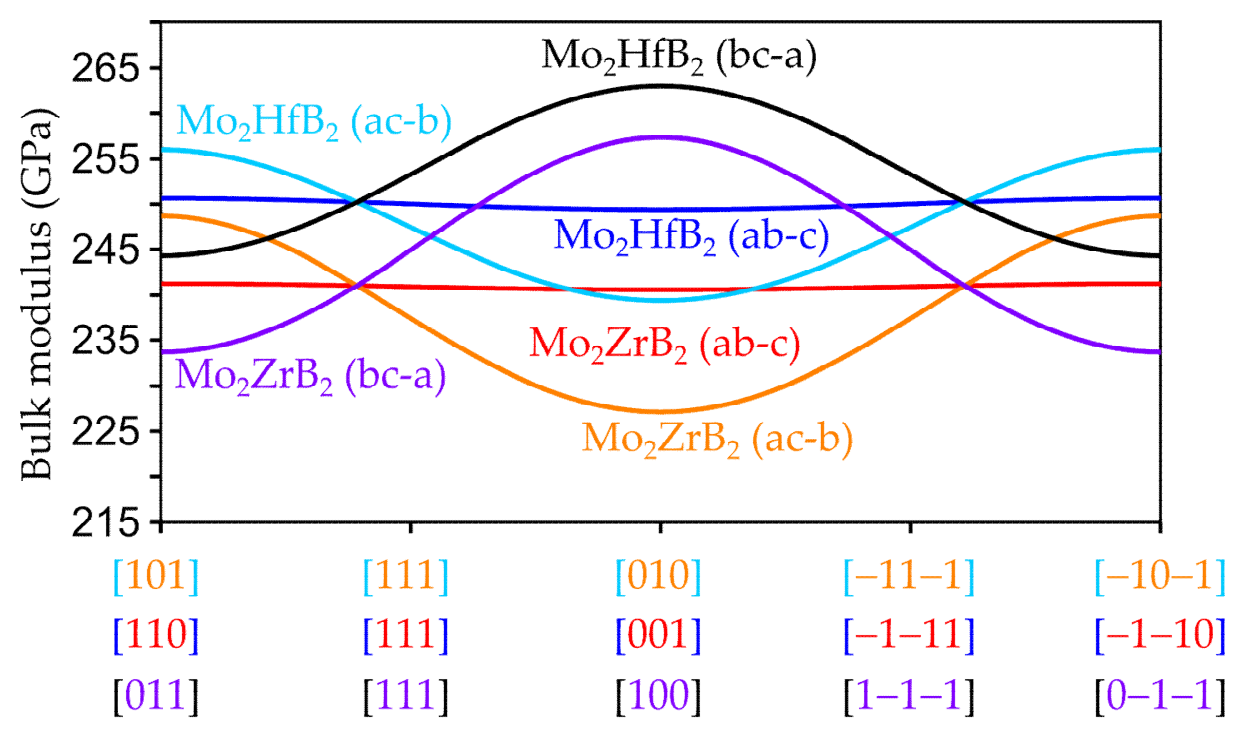

Crystallographic direction

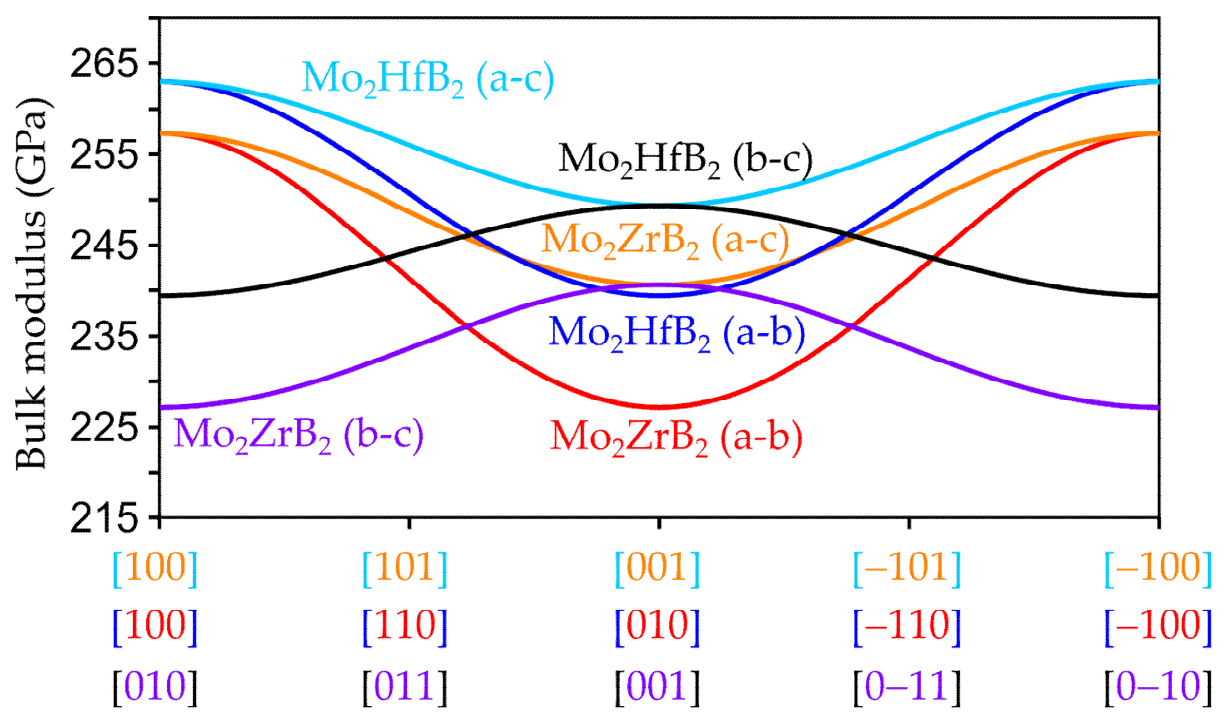

Crystallographic direction

Figure 4. Anisotropic bulk modulus in the $a-b, a-c$ and $b-c$-plane (lower part) and the $a b-c, a c-b$ and $b c-a$-plane (upper part) of $\mathrm{Mo}_{2} \mathrm{ZrB}_{2}$ (red, orange and purple) and $\mathrm{Mo}_{2} \mathrm{HfB}_{2}$ (blue, cyan and black), respectively, both with the $\mathrm{AlMn}_{2} \mathrm{~B}_{2}$-type structure.

The anisotropic shear modulus $G$ is shown in Figure 5.

The shear modulus near the $\{011\}$ direction in the $b$-c plane of $\mathrm{Mo}_{2} \mathrm{ZrB}_{2}$ and $\mathrm{Mo}_{2} \mathrm{HfB}_{2}$ is $139.93 \mathrm{GPa}$ and $152.27 \mathrm{GPa}$, respectively, and it is the minimum. The maximum of the shear modulus is observed near the $\{101\}$ direction in the $a-c$ plane, as it is $153.26 \mathrm{GPa}$ and $164.12 \mathrm{GPa}$, for $\mathrm{Mo}_{2} \mathrm{ZrB}_{2}$ and $\mathrm{Mo}_{2} \mathrm{HfB}_{2}$, respectively.

The anisotropic shear modulus of $\mathrm{Mo}_{2} \mathrm{ZrB}_{2}$ and $\mathrm{Mo}_{2} \mathrm{HfB}_{2}$ within the $a b-c$ plane, as well as the $a-c$ plane, behaves differently. While within the $a b-c$ plane, $G$ of $\mathrm{Mo}_{2} \mathrm{HfB}_{2}$ is only slightly changing, while $G$ of $\mathrm{Mo}_{2} \mathrm{ZrB}_{2}$ shows clear a clear minimum near the $\{111\}$ direction and maxima near $\{110\}$ and $\{001\}$. Within the $a-c$ plane, $G$ of $\mathrm{Mo}_{2} \mathrm{ZrB}_{2}$ is almost constant between the $\{101\}$ and $\{001\}$ directions, while $G$ of $\mathrm{Mo}_{2} \mathrm{HfB}_{2}$ shows clear minima and maxima between these directions. This different behavior of the 
shear modulus of $\mathrm{Mo}_{2} \mathrm{ZrB}_{2}$ and $\mathrm{Mo}_{2} \mathrm{HfB}_{2}$ also effects the Young's modulus and Vickers hardness in the same planes.

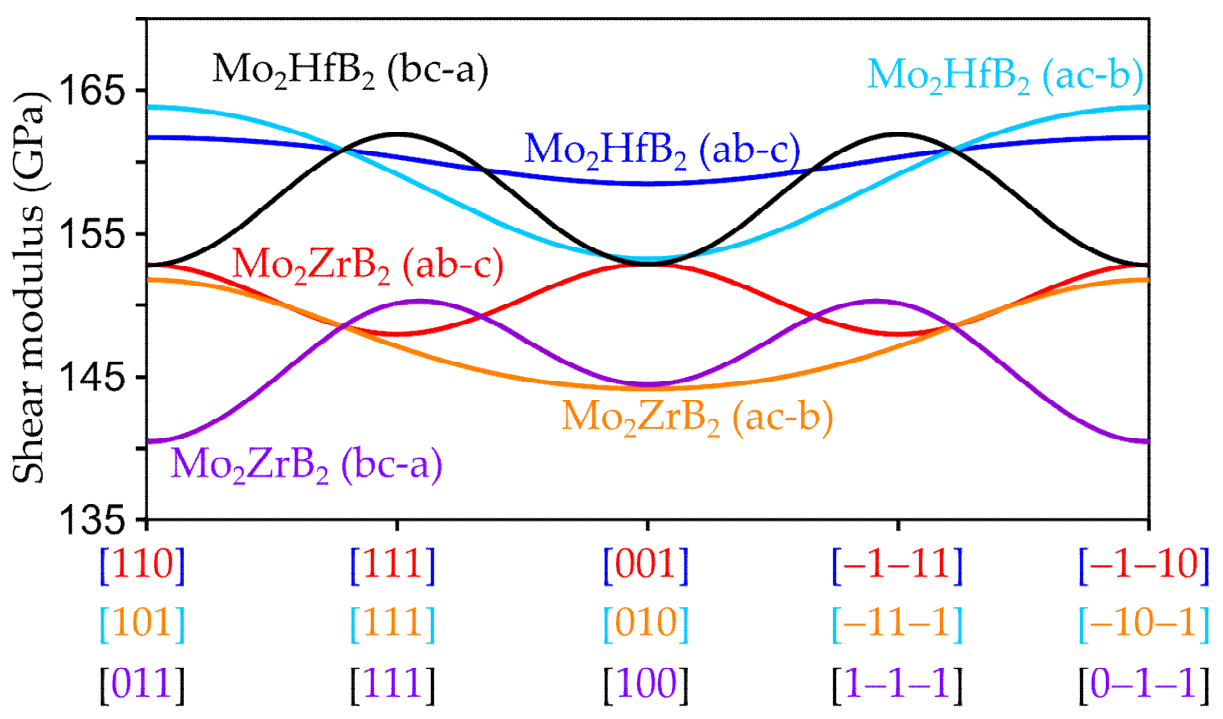

Crystallographic direction

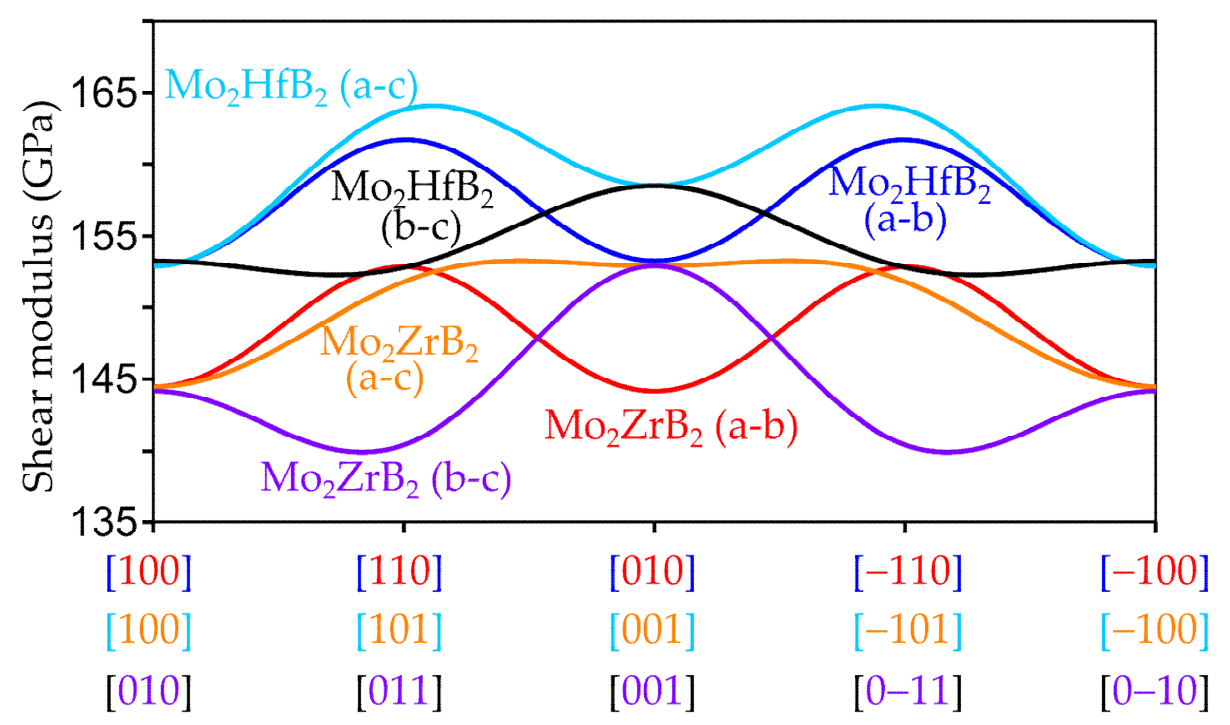

Crystallographic direction

Figure 5. Anisotropic shear modulus in the $a-b, a-c$ and $b-c$-plane (lower part) and the $a b-c, a c-b$ and $b c$-a-plane (upper part) of $\mathrm{Mo}_{2} \mathrm{ZrB}_{2}$ (red, orange and purple) and $\mathrm{Mo}_{2} \mathrm{HfB}_{2}$ (blue, cyan and black), respectively, both with the $\mathrm{AlMn}_{2} \mathrm{~B}_{2}$-type structure.

Using the maximum and minimum shear modulus of $\mathrm{Mo}_{2} \mathrm{ZrB}_{2}$ and $\mathrm{Mo}_{2} \mathrm{HfB}_{2}$, the anisotropy of $G$ is 0.10 and 0.08 for $\mathrm{Mo}_{2} \mathrm{ZrB}_{2}$ and $\mathrm{Mo}_{2} \mathrm{HfB}_{2}$, respectively (see also Table 3).

The anisotropic Young's modulus is shown in Figure 6. 


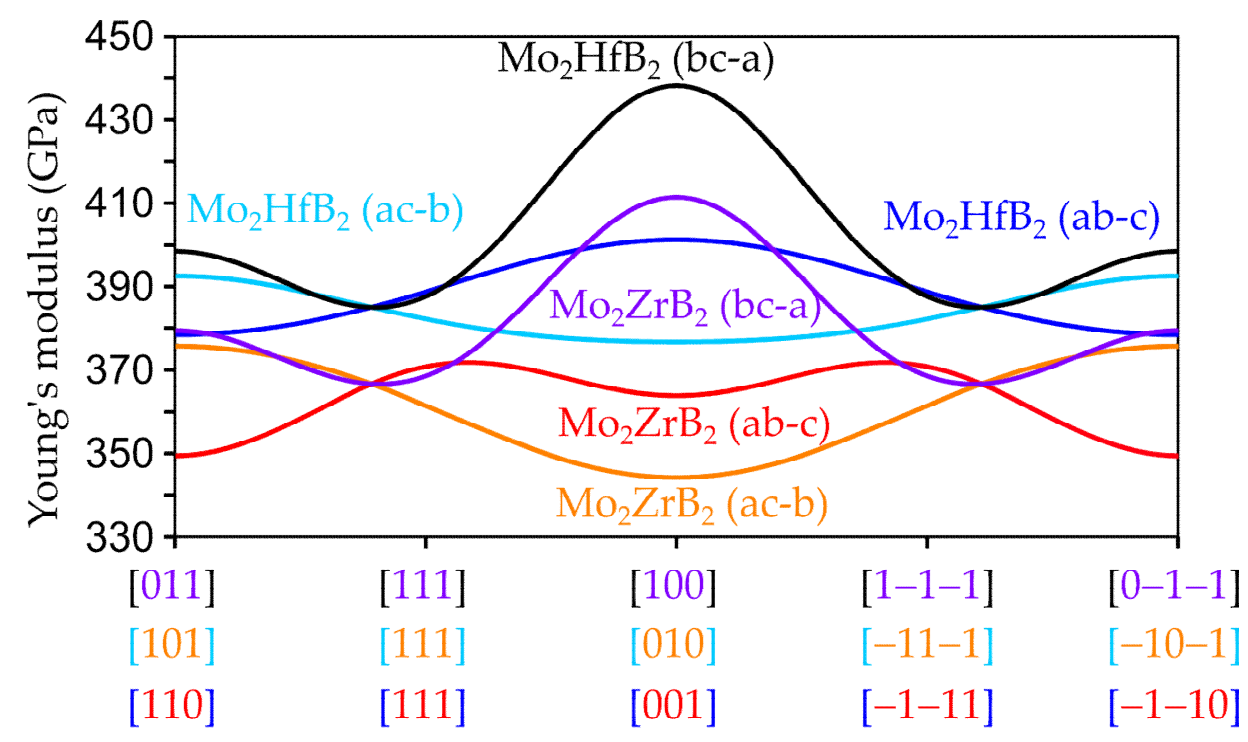

Crystallographic direction

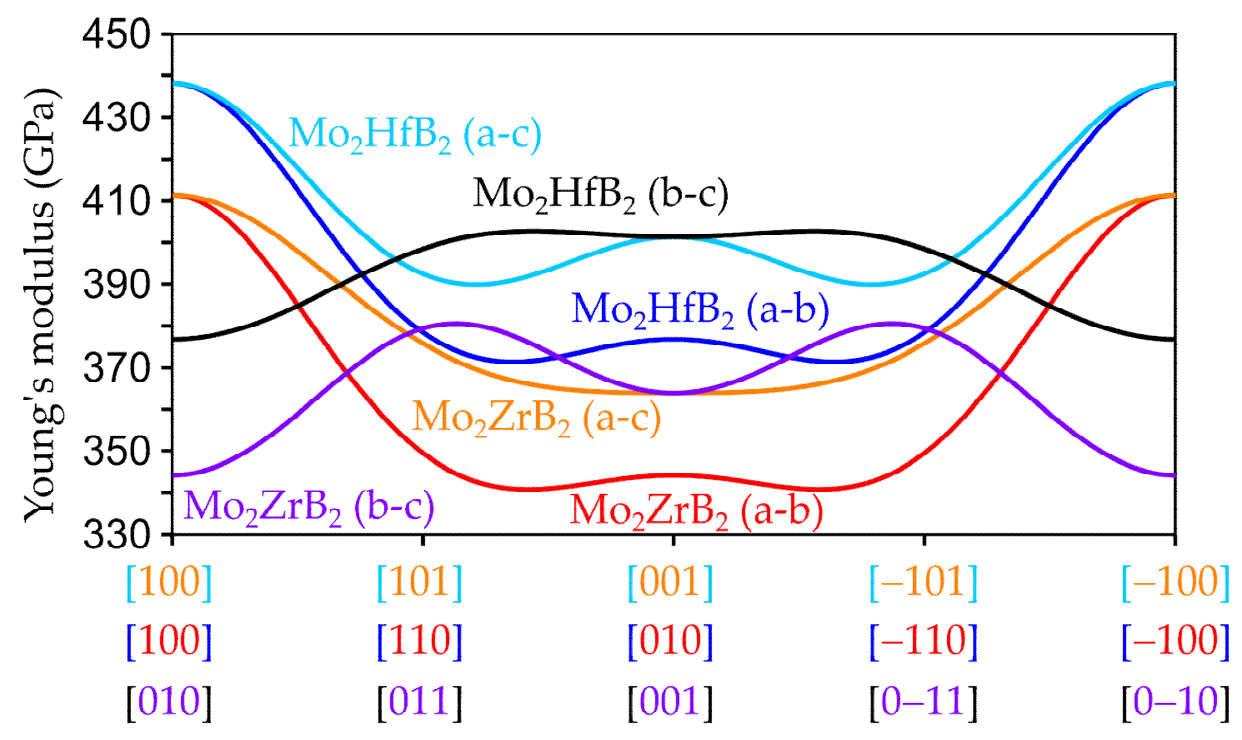

Crystallographic direction

Figure 6. Anisotropic Young's modulus in the $a-b, a-c$ and $b$-c-plane (lower part) and the $a b-c, a c-b$ and $b c-a$-plane (upper part) of $\mathrm{Mo}_{2} \mathrm{ZrB}_{2}$ (red, orange and purple) and $\mathrm{Mo}_{2} \mathrm{HfB}_{2}$ (blue, cyan and black), respectively, both with the $\mathrm{AlMn}_{2} \mathrm{~B}_{2}$-type structure.

The Young's modulus of $\mathrm{Mo}_{2} \mathrm{ZrB}_{2}$ and $\mathrm{Mo}_{2} \mathrm{HfB}_{2}$ near the $\{110\}$ direction in the $a$ - $b$-plane is the minimum, as $Y$ is $340.83 \mathrm{GPa}$ and $371.43 \mathrm{GPa}$, respectively. The maximum of the Young's modulus of $\mathrm{Mo}_{2} \mathrm{ZrB}_{2}$ and $\mathrm{Mo}_{2} \mathrm{HfB}_{2}$ is $411.43 \mathrm{GPa}$ and $438.21 \mathrm{GPa}$, respectively, and it is found along the $\{100\}$ direction.

Taking into account the maximum and minimum Young's modulus of $\mathrm{Mo}_{2} \mathrm{ZrB}_{2}$ and $\mathrm{Mo}_{2} \mathrm{HfB}_{2}$, the anisotropy of $Y$ is 0.21 and 0.18 for $\mathrm{Mo}_{2} \mathrm{ZrB}_{2}$ and $\mathrm{Mo}_{2} \mathrm{HfB}_{2}$, respectively (see also Table 3).

In Figure 7 the anisotropic Vickers hardness $H^{V}$ of $\mathrm{Mo}_{2} \mathrm{ZrB}_{2}$ and $\mathrm{Mo}_{2} \mathrm{HfB}_{2}$ is shown. 


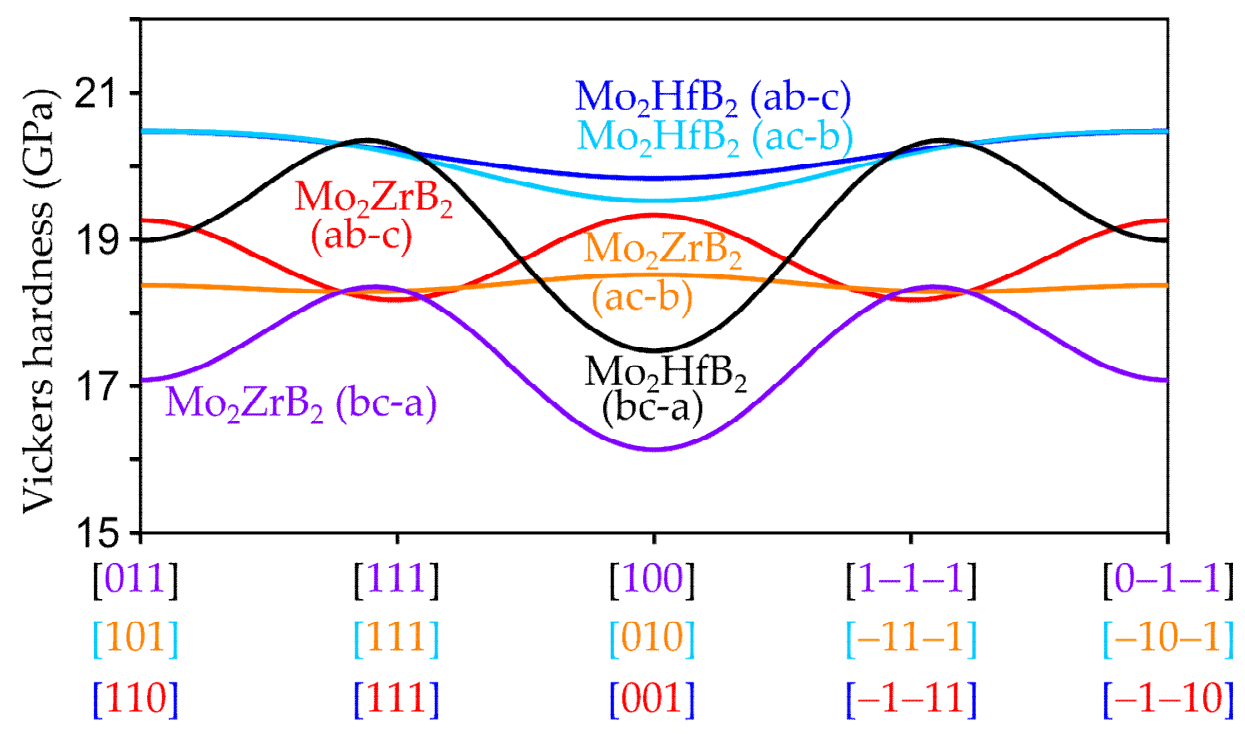

Crystallographic direction

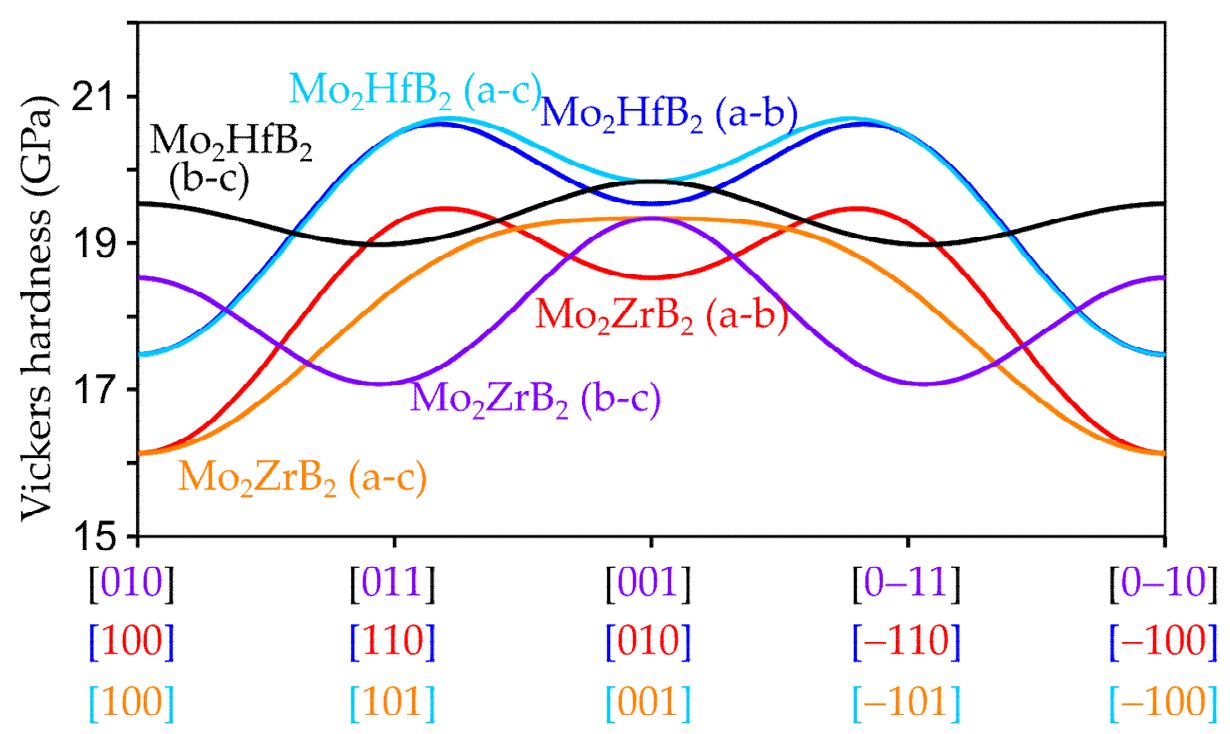

Crystallographic direction

Figure 7. Anisotropic Vickers hardness in the $a-b, a-c$ and $b$-c-plane (lower part) and the $a b-c, a c-b$ and $b c$ - $a$-plane (upper part) of $\mathrm{Mo}_{2} \mathrm{ZrB}_{2}$ (red, orange and purple) and $\mathrm{Mo}_{2} \mathrm{HfB}_{2}$ (blue, cyan and black), respectively, both with the $\mathrm{AlMn}_{2} \mathrm{~B}_{2}$-type structure.

The anisotropic Vickers hardness was calculated using the bulk and shear modulus according to the formula of Tian et al. [52]. The minimum of the Vickers hardness of $\mathrm{Mo}_{2} \mathrm{ZrB}_{2}$ and $\mathrm{Mo}_{2} \mathrm{HfB}_{2}$ is along the $\{100\}$ direction, as $H^{V}$ is $16.13 \mathrm{GPa}$ and $17.48 \mathrm{GPa}$, respectively. However, the maximum of the Vickers hardness of $\mathrm{Mo}_{2} \mathrm{ZrB}_{2}$ and $\mathrm{Mo}_{2} \mathrm{HfB}_{2}$ is along different crystallographic directions. Near the $\{110\}$ direction in the $a-b$ plane, the maximum Vickers hardness of $\mathrm{Mo}_{2} \mathrm{ZrB}_{2}$ is $19.47 \mathrm{GPa}$, while for the same direction, the $H^{V}$ of $\mathrm{Mo}_{2} \mathrm{HfB}_{2}$ is $20.62 \mathrm{GPa}$, which is not the maximum $H^{V}$ of $\mathrm{Mo}_{2} \mathrm{HfB}_{2}$. The maximum Vickers hardness of $\mathrm{Mo}_{2} \mathrm{HfB}_{2}$ is near the $\{101\}$ direction in the $a-c$ plane as $H^{V}$ is $20.70 \mathrm{GPa}$. In the same direction, $\mathrm{H}^{V}$ of $\mathrm{Mo}_{2} \mathrm{ZrB}_{2}$ is $18.85 \mathrm{GPa}$. The experimental Vickers hardness of $\mathrm{Mo}_{2} \mathrm{ZrB}_{2}$ is $19.50 \mathrm{GPa}[10,14]$; thus, the DFT calculated numbers of the anisotropic Vickers hardness 
are in very good agreement with the experiment. Unfortunately for $\mathrm{Mo}_{2} \mathrm{HfB}_{2}$, no experimental Vickers hardness is currently known.

Taking into account the maximum and minimum Vickers hardness of $\mathrm{Mo}_{2} \mathrm{ZrB}_{2}$ and $\mathrm{Mo}_{2} \mathrm{HfB}_{2}$, the anisotropy of $H^{V}$ is 0.21 and 0.18 for $\mathrm{Mo}_{2} \mathrm{ZrB}_{2}$ and $\mathrm{Mo}_{2} \mathrm{HfB}_{2}$, respectively, which is similar to the one of $Y$ (see also Table 3).

In summary, the anisotropic bulk, shear and Young's modulus as well as the Vickers hardness of $\mathrm{Mo}_{2} \mathrm{HfB}_{2}$ are for the same directions in the same plane higher than the elastic moduli of $\mathrm{Mo}_{2} \mathrm{ZrB}_{2}$, which might be due to their respective interatomic bonding conditions. This hypothesis will be investigated in Section 3.3. The maxima of the bulk and Young's modulus of $\mathrm{Mo}_{2} \mathrm{ZrB}_{2}$ and $\mathrm{Mo}_{2} \mathrm{HfB}_{2}$ were observed for the $\{100\}$ direction, while the maximum of the shear modulus of $\mathrm{Mo}_{2} \mathrm{ZrB}_{2}$ and $\mathrm{Mo}_{2} \mathrm{HfB}_{2}$ was found near the $\{101\}$ direction. The maximum of the Vickers hardness of $\mathrm{Mo}_{2} \mathrm{ZrB}_{2}$ was found near the $\{110\}$ direction, while the maximum of the Vickers hardness of $\mathrm{Mo}_{2} \mathrm{HfB}_{2}$ is near the $\{101\}$ direction. The minimum of the bulk modulus of $\mathrm{Mo}_{2} \mathrm{ZrB}_{2}$ and $\mathrm{Mo}_{2} \mathrm{HfB}_{2}$ is along the $\{010\}$ direction, while the minimum of the shear modulus of these borides is along the $\{011\}$ direction. The minimum of the Young's modulus of $\mathrm{Mo}_{2} \mathrm{ZrB}_{2}$ and $\mathrm{Mo}_{2} \mathrm{HfB}_{2}$ is along the $\{110\}$ direction, while for the Vickers hardness the minimum is along the $\{100\}$ direction.

Also, the elastic moduli of $\mathrm{Mo}_{2} \mathrm{HfB}_{2}$ are less anisotropic than the elastic moduli of $\mathrm{Mo}_{2} \mathrm{ZrB}_{2}$. To better compare this with the Universal Anisotropy Index $A^{U}$, one can also define a $B$ and $G$ averaged anisotropy index and for $\mathrm{Mo}_{2} \mathrm{HfB}_{2}$; this is $0.09\left(A^{U}=0.02\right)$, while for $\mathrm{Mo}_{2} \mathrm{ZrB}_{2}$ it is $0.12\left(A^{U}=0.03\right)$. The similarity of the calculated $B$ and $G$ averaged anisotropy index and the Universal Anisotropy Index indicates that both indexes can be used to determine the elastic anisotropy, and that $\mathrm{Mo}_{2} \mathrm{ZrB}_{2}$ and $\mathrm{Mo}_{2} \mathrm{HfB}_{2}$ show only slightly elastic anisotropic behavior.

\subsection{Influence of the Chemical Bonding on the Elastic Properties}

In this section, we will use the integrated crystal orbital Hamilton population (ICOHP) as a measure for the strength of the chemical bonding to explain the differences of the elastic properties between $\mathrm{Mo}_{2} \mathrm{ZrB}_{2}$ and $\mathrm{Mo}_{2} \mathrm{HfB}_{2}$. The respective ICOHPs per bond type are presented in Table 4 .

Table 4. Integrated crystal orbital Hamilton population (ICOHPs) per formula unit of the Mo-Mo, Mo-M, Mo-B M-M, M-B and B-B bonds $\left(\mathrm{M}=\mathrm{Zr}\right.$, Hf) in $\mathrm{Mo}_{2} \mathrm{ZrB}_{2}$ and $\mathrm{Mo}_{2} \mathrm{HfB}_{2}$.

\begin{tabular}{|c|c|c|c|}
\hline Bonds (Number) & Direction Along Axis & $\begin{array}{c}\text { ICOHP of the Bonds in } \\
\mathrm{Mo}_{2} \mathrm{ZrB}_{2}(\mathrm{eV})\end{array}$ & $\begin{array}{c}\text { ICOHP of the Bonds in } \\
\mathrm{Mo}_{2} \mathrm{HfB}_{2}(\mathrm{eV})\end{array}$ \\
\hline B-B $(2 \times)$ & $a b$ & -6.56 & -6.67 \\
\hline M-B $(2 \times)$ & $b$ & -2.51 & -2.79 \\
\hline Mo-B, short $(4 \times)$ & $a c$ & -9.09 & -8.92 \\
\hline Mo-B, long $(2 \times)$ & $b c$ & -3.80 & -3.74 \\
\hline M-M, short $(2 \times)$ & $a$ & -1.54 & -1.66 \\
\hline M-M, long $(2 \times)$ & $c$ & -1.51 & -1.58 \\
\hline Mo-M $(4 \times)$ & $a b-c$ & -5.24 & -5.62 \\
\hline Mo-Mo, short $(2 \times)$ & $a b$ & -2.23 & -2.13 \\
\hline Mo-Mo, medium $(2 \times)$ & $a$ & -1.65 & -1.63 \\
\hline Mo-Mo, long $(2 \times)$ & $c$ & -1.29 & -1.24 \\
\hline Mo-Mo, longest $(1 \times)$ & $b$ & -0.26 & -0.36 \\
\hline Sum & & -35.68 & -36.33 \\
\hline
\end{tabular}

The ICOHP of the bonds B-B short and long M-M ( $\mathrm{M}=\mathrm{Zr}, \mathrm{Hf})$, Mo-M and longest Mo-Mo are higher in $\mathrm{Mo}_{2} \mathrm{HfB}_{2}$ than in $\mathrm{Mo}_{2} \mathrm{ZrB}_{2}$, while in $\mathrm{Mo}_{2} \mathrm{ZrB}_{2}$, the short and long Mo-B bonds and the short, medium and long Mo-Mo bonds are stronger than in $\mathrm{Mo}_{2} \mathrm{HfB}_{2}$. If one sums up these ICOHPs, it becomes clear that the chemical bonding in $\mathrm{Mo}_{2} \mathrm{HfB}_{2}$ is stronger than in $\mathrm{Mo}_{2} \mathrm{ZrB}_{2}$. This might be the explanation why the elastic moduli of $\mathrm{Mo}_{2} \mathrm{HfB}_{2}$ are larger than the elastic moduli of $\mathrm{Mo}_{2} \mathrm{ZrB}_{2}$. A similar correlation of ICOHP per formula unit and the elastic moduli were also found in other $\mathrm{A}_{2} \mathrm{MB}_{2}$ borides $(\mathrm{A}=\mathrm{Nb}, \mathrm{Ta} ; \mathrm{M}=\mathrm{Fe}, \mathrm{Ru}, \mathrm{Os})[56,58]$. 
However, the ICOHPs of individual bonds alone are not sufficient to explain the different behavior of the anisotropic shear modulus $G$ of $\mathrm{Mo}_{2} \mathrm{ZrB}_{2}$ and $\mathrm{Mo}_{2} \mathrm{HfB}_{2}$ within the $a b-c$ and $a-c$ plane. A closer look at the bonding situation reveals that the Mo-Mo, Mo-M and M-M bonds are along the $a, c, a b$ and $a b-c$ directions and, thus, for the directions, the different behavior of $G$ was observed. The DOSs of $\mathrm{Mo}$ and $\mathrm{Zr}$ in $\mathrm{Mo}_{2} \mathrm{ZrB}_{2}$ differ from the DOSs of $\mathrm{Mo}$ and $\mathrm{Hf}$ in $\mathrm{Mo}_{2} \mathrm{HfB}_{2}$, especially in the area between $-5 \mathrm{eV}$ and $0 \mathrm{eV}$ (see Figure 2). Taking a look on the Phonon-Density-of-States of $\mathrm{Mo}_{2} \mathrm{ZrB}_{2}$ and $\mathrm{Mo}_{2} \mathrm{HfB}_{2}$ (Figure 3), the PDSs of Mo and $\mathrm{Zr}$ show a similar dispersion between $5 \mathrm{THz}$ and $8 \mathrm{THz}$, while, because of the higher atomic weight, the PDS of Hf is mainly at lower frequencies below $5 \mathrm{THz}$ and shows no similar dispersion like the PDS of Mo. Therefore, these differences in the DOSs and the PDSs might explain the different anisotropic behavior of the shear modulus of $\mathrm{Mo}_{2} \mathrm{ZrB}_{2}$ and $\mathrm{Mo}_{2} \mathrm{HfB}_{2}$. The influence of the electronic structure on the shear modulus was also observed in other $\mathrm{A}_{2} \mathrm{MB}_{2}$ borides $(\mathrm{A}=\mathrm{Nb}, \mathrm{Ta} ; \mathrm{M}=\mathrm{Fe}, \mathrm{Ru}, \mathrm{Os})[56,58]$.

\section{Conclusions}

In this work, we predicted the crystal structure of $\mathrm{Mo}_{2} \mathrm{ZrB}_{2}$ and $\mathrm{Mo}_{2} \mathrm{HfB}_{2}$ to be of the $\mathrm{AlMn}_{2} \mathrm{~B}_{2}$ type structure, as there are no signs of electronic or dynamical instability found in the DOS and the PDS, respectively. Further, we investigated the elastic properties of these ternary borides and the isotropic and anisotropic elastic moduli like the bulk, shear and Young's modulus, as well as the Vickers hardness, which of $\mathrm{Mo}_{2} \mathrm{HfB}_{2}$ are higher than those of $\mathrm{Mo}_{2} \mathrm{ZrB}_{2}$ because of the chemical bonding situation. Also, it was shown that $\mathrm{Mo}_{2} \mathrm{HfB}_{2}$ is less elastically anisotropic than $\mathrm{Mo}_{2} \mathrm{ZrB}_{2}$.

Author Contributions: Conceptualization, R.S.T. and M.K.; methodology, R.S.T.; investigation, R.S.T.; writingoriginal draft preparation, R.S.T. and M.K.; writing—review and editing, R.S.T. and M.K.; visualization, R.S.T.; funding acquisition, M.K. All authors have read and agreed to the published version of the manuscript.

Funding: The financial support by the German Research Foundation (DFG) in the framework of project 438070774 is greatly acknowledged.

Acknowledgments: We thank V. Bolbut for fruitful discussions on the existence and stability of phases in the systems Mo-Hf-B and Mo-Zr-B. R.T. also thanks the URZ OVGU Magdeburg for calculation power and time.

Conflicts of Interest: The authors declare no conflict of interest.

\section{References}

1. Dimiduk, D.M.; Perepezko, J.H. Mo-Si-B Alloys: Developing a Revolutionary Turbine-Engine Material. MRS Bull. 2003, 28, 639-645. [CrossRef]

2. Kruzic, J.J.; Schneibel, J.H.; Ritchie, R.O. Ambient- to elevated-temperature fracture and fatigue properties of Mo-Si-B alloys: Role of microstructure. Metall. Mater. Trans. A 2005, 36, 2393-2402. [CrossRef]

3. Yu, X.J.; Kumar, K.S. The tensile response of Mo, Mo-Re and Mo-Si solid solutions. Int. J. Refract. Hard Met. 2013, 41, 329-338. [CrossRef]

4. Perepezko, J.H. The hotter the engine, the better. Science 2009, 326, 1068-1069. [CrossRef]

5. Rioult, F.A.; Imhoff, S.D.; Sakidja, R.; Perepezko, J.H. Transient oxidation of Mo-Si-B alloys: Effect of the microstructure size scale. Acta Mater. 2009, 57, 4600-4613. [CrossRef]

6. Krüger, M.; Jain, P.; Kumar, K.S.; Heilmaier, M. Correlation between microstructure and properties of fine grained $\mathrm{Mo}_{-} \mathrm{Mo}_{3} \mathrm{Si}_{-} \mathrm{Mo}_{5} \mathrm{SiB}_{2}$ alloys. Intermetallics 2014, 48. [CrossRef]

7. Schliephake, D.; Azim, M.; von Klinski-Wetzel, K.; Gorr, B.; Christ, H.J.; Bei, H.; George, E.P.; Heilmaier, M. High-temperature creep and oxidation behavior of Mo-Si-B alloys with high Ti contents. Metall. Mater. Trans. A Phys. Metall. Mater. Sci. 2014, 45, 1102-1111. [CrossRef]

8. Bolbut, V.; Seils, S.; Boll, T.; Chassaing, D.; Krüger, M. Controversial discussion on the existence of the Hf and Zr monoborides and experimental proof by atom probe tomography. Materialia 2019, 6, 100322. [CrossRef]

9. Bolbut, V.; Bogomol, I.; Loboda, P.; Krüger, M. Microstructure and mechanical properties of a directionally solidified Mo-12Hf-24B alloy. J. Alloys Compd. 2018, 735, 2324-2330. [CrossRef]

10. Bolbut, V.; Bogomol, I.; Bauer, C.; Krüger, M. Gerichtet erstarrte Mo-Zr-B-Legierungen/ Directionally solidified Mo-Zr-B alloys. Materialwissenschaft und Werkstofftechnik 2017, 48, 1113-1124. [CrossRef] 
11. Smokovych, I.; Bolbut, V.; Krüger, M.; Scheffler, M. Tailored Oxidation Barrier Coatings for Mo-Hf-B and Mo-Zr-B Alloys. Materials 2019, 12, 2215. [CrossRef] [PubMed]

12. Rogl, B. Boron-Molybdenum-Zirconium. In Numerical Data and Functional Relationships in Science and Technology; Effenberg, G., Madelung, O., Eds.; Springer: Berlin, Germany, 2010; pp. 72-82.

13. Rogl, P. Boron-Hafnium-Molybdenum. In Refractory Metal Systems; Martienssen, W., Effenberg, G., Ilyenko, S., Eds.; Springer: Berlin/Heidelberg, Germany, 2009; pp. 695-707.

14. Bolbut, V. Development of Mo-Hf-B and Mo-Zr-B Alloys for High Temperature Application. Ph.D. Thesis, Otto-von-Guericke University Magdeburg, Magdeburg, Germany, 2018.

15. Bolbut, V.; Seils, S.; Chassaing, D.; Boll, T.; Krüger, M. Assessment of ternary borides in the Mo-Hf-B and Mo-Zr-B systems and new description on phase equilibria. Unpublished work.

16. Schmidt, M.U.; Englert, U. Prediction of crystal structures. J. Chem. Soc. Dalton Trans. 1996, 10, $2077-2082$. [CrossRef]

17. Kirkpatrick, S.; Gelatt, C.D., Jr.; Vecchi, M.P. Optimization by Simulated Annealing. Science 1983, 220, 671-680. [CrossRef] [PubMed]

18. Oganov, A.R.; Glass, C.W. Crystal structure prediction using ab initio evolutionary techniques: Principles and applications. J. Chem. Phys. 2006, 124, 244704. [CrossRef] [PubMed]

19. Becher, H.J.; Krogmann, K.; Peisker, E. Über das ternäre Borid $\mathrm{Mn}_{2} \mathrm{AlB}_{2}$. Z. Anorg. Allg. Chem. 1966, 344, 140-147. (In German) [CrossRef]

20. Rieger, W.; Nowotny, H.; Benesovsky, F. Die Kristallstruktur von $\mathrm{Mo}_{2} \mathrm{FeB}_{2}$. Monatsh. Chem. 1964, 95, 1502-1503. (In German) [CrossRef]

21. Mbarki, M.; Touzani, R.S.; Fokwa, B.P.T. $\mathrm{Nb}_{2} \mathrm{OsB}_{2}$, with a new twofold superstructure of the $\mathrm{U}_{3} \mathrm{Si}_{2}$ type: Synthesis, crystal chemistry and chemical bonding. J. Sol. Sta. Chem. 2013, 203, 304-309. [CrossRef]

22. Gravereau, P.; Mirambet, F.; Chevalier, B.; Weill, F.; Fournès, L.; Laffargue, D.; Bourée, F.; Etourneau, J. Crystal structure of $\mathrm{U}_{2} \mathrm{Pt}_{2} \mathrm{Sn}$ : A new derivative of the tetragonal $\mathrm{U}_{3} \mathrm{Si}_{2}$-type structure. J. Mater. Chem. 1994, 4, 1893-1895. [CrossRef]

23. Rogl, P. Über SE-Metall-Kobaltboride. Monatsh. Chem. 1973, 104, 1623-1631. (In German) [CrossRef]

24. Kotzott, D.; Ade, M.; Hillebrecht, H. Synthesis and Crystal Structures of alpha- and beta-Modifications of $\mathrm{Cr}_{2} \mathrm{IrB}_{2}$ containing $\mathrm{B}_{4}$-Chains, $\tau$-Borides $\mathrm{Cr}_{23-\mathrm{x}} \mathrm{Ir}_{\mathrm{x}} \mathrm{B}_{6}$ and $\mathrm{Cr}_{2}$ B. Sol. Sta. Sci. 2008, 10, 291-302. [CrossRef]

25. Rogl, P.; Beneshovsky, F.; Nowotny, H. Über einige Komplexboride mit Platinmetallen. Monatsh. Chem. 1972, 103, 965-989. (In German) [CrossRef]

26. Bruskov, V.A.; Gubich, I.B.; Kuz'ma, Y.B. Crystal structure of a new boride $\mathrm{HoNi}_{2} \mathrm{~B}_{2}$. Kristallografiya 1991, $36,1123-1125$.

27. Rieger, W.; Nowotny, H.; Benesovsky, F. Die Kristallstruktur von $\mathrm{W}_{2} \mathrm{CoB}_{2}$ und isotypen Phasen. Monatsh. Chem. 1966, 97, 378-382. (In German) [CrossRef]

28. Vande Vondele, J.; Krack, M.; Mohamed, F.; Parrinello, M.; Chassaing, T.; Hutter, J. Quickstep: Fast and accurate density functional calculations using a mixed Gaussian and plane waves approach. Commun. Comput. Phys. 2005, 167, 103-128. [CrossRef]

29. Hutter, J.; Ianuzzi, M.; Schiffmann, F.; Vande Vondele, J. CP2k: Atomistic Simulations of Condensed Matter System. WIRES Comput. Mol. Sci. 2014, 4, 15-25. [CrossRef]

30. Lippert, G.; Hutter, J.; Parrinello, M. A hybrid Gaussian and plane wave density functional scheme. Mol. Phys. 1997, 92, 477-488. [CrossRef]

31. Vande Vondele, J.; Hutter, J. Gaussian basis sets for accurate calculations on molecular systems in gas and condensed phases. J. Chem. Phys. 2007, 127, 114105. [CrossRef]

32. Goedecker, S.; Teter, M.; Hutter, J. Separable dual-space Gaussian pseudopotentials. Phys. Rev. B 1996, 54, 1703-1710. [CrossRef]

33. Hartwigsen, C.; Goedecker, S.; Hutter, J. Relativistic separable dual-space Gaussian pseudopotentials from H to Rn. Phys. Rev. B 1998, 58, 3641-3662. [CrossRef]

34. Krack, M. Pseudopotentials for $\mathrm{H}$ to $\mathrm{Kr}$ optimized for gradient-corrected exchange-correlation functionals. Theor. Chem. Acc. 2005, 114, 145-152. [CrossRef]

35. Monkhorst, H.J.; Pack, J.D. Special points for Brillouin-zone integrations. Phys. Rev. B 1976, 13, 5188-5192. [CrossRef]

36. Perdew, J.P.; Burke, K.; Ernzerhof, M. Generalized Gradient Approximation Made Simple. Phys. Rev. Lett. 1996, 77, 3865-3868. [CrossRef] [PubMed] 
37. Togo, A.; Tanaka, I. First principles phonon calculations in materials science. Scripta Mater. 2015, 108, 1-5. [CrossRef]

38. Touzani, R.S.; Mbarki, M.; Chen, X.; Fokwa, B.P.T. Peierls-Distorted Ru-Chains and Boron Dumbbells in $\mathrm{Nb}_{2} \mathrm{RuB}_{2}$ and $\mathrm{Ta}_{2} \mathrm{RuB}_{2}$ from First-Principles Calculations and Experiments. Eur. J. Inorg. Chem. 2016, 25, 4104-4110. [CrossRef]

39. Andersen, O.K.; Skriver, H.L.; Nohl, H.; Johansson, B. Electronic structure of transition metal compounds; ground-state properties of the $3 d$-monoxides in the atomic sphere approximation. Pure Appl. Chem. 1980, 52, 93-118. [CrossRef]

40. Andersen, O.K.; Jepsen, O. Explicit, First-Principles Tight-Binding Theory. Phys. Rev. Lett. 1984, 53, $2571-2574$. [CrossRef]

41. Perdew, J.P.; Chevary, J.A.; Vosko, S.H.; Jackson, K.A.; Pederson, M.R.; Singh, D.J.; Fiolhais, C. Atoms, molecules, solids, and surfaces: Applications of the generalized gradient approximation for exchange and correlation. Phys. Rev. B 1992, 46, 6671-6687. [CrossRef]

42. Dronskowski, R.; Blöchl, P. Crystal orbital Hamilton populations (COHP): Energy-resolved visualization of chemical bonding in solids based on density-functional calculations. J. Phys. Chem. 1993, 97, 8617-8624. [CrossRef]

43. Giannozzi, P.; Baroni, S.; Bonini, N.; Calandra, M.; Car, R.; Cavazzoni, C.; Ceresoli, D.; Chiarotti, G.L.; Cococcioni, M.; Dabo, I.; et al. Quantum ESPRESSO: A modular and open-source software project for quantum simulations of materials. J. Phys. Condens. Matter 2009, 21, 395502. [CrossRef]

44. Giannozzi, P.; Andreussi, O.; Brumme, T.; Bunau, O.; Buongiorno Nardelli, M.; Calandra, M.; Car, R.; Cavazzoni, C.; Ceresoli, D.; Cococcioni, M.; et al. Advanced capabilities for materials modelling with Quantum ESPRESSO. J. Phys. Condens. Matter 2017, 29, 465901. [CrossRef]

45. Blöchl, P.E. Projector augmented-wave method. Phys. Rev. B 1994, 50, 17953-17979. [CrossRef]

46. Dal Corso, A. Pseudopotentials periodic table: From H to Pu. Comput. Mat. Sci. 2014, 95, 337-350. [CrossRef]

47. Marzari, N.; Vanderbilt, D.; De Vita, A.; Payne, M.C. Thermal Contraction and Disordering of the Al(110) Surface. Phys. Rev. Lett. 1999, 82, 3296-3299. [CrossRef]

48. Thermo_pw is an Extension of the Quantum ESPRESSO (QE) Package Which Provides an Alternative Organization of the QE Work-flow for the Most Common Tasks. Available online: https:/dalcorso.github.io/ thermo_pw/ (accessed on 17 August 2020).

49. Voigt, W. Lehrbuch der Kristallphysik; Springer: Berlin/Leipzig, Germany, 1928. (In German)

50. Reuss, A. Berechnung der Fließgrenze von Mischkristallen auf Grund der Plastizitätsbedingung für Einkristalle. Z. Angew Math. Mech. 1929, 9, 49-58. (In German) [CrossRef]

51. Hill, R. The Elastic Behaviour of a Crystalline Aggregate. Proc. Phys. Soc. A 1952, 65, 349-354. [CrossRef]

52. Tian, Y.; Xu, B.; Zhao, Z. Microscopic theory of hardness and design of novel superhard crystals. Int. J. Refract. Met. Hard Mater. 2012, 33, 93-106. [CrossRef]

53. Nye, J.F. Physical Properties of Crystals: Their Representation by Tensors and Matrices; Oxford University Press: New York, NY, USA, 1985.

54. Wu, D.-H.; Wang, H.-C.; Wei, L.-T.; Pan, R.-K.; Tang, B.-Y. First-principles study of structural stability and elastic properties of $\mathrm{MgPd}_{3}$ and its hydride. J. Magnes. Alloy 2014, 2, 165-174. [CrossRef]

55. Ranganathan, S.I.; Ostoja-Starzewski, M. Universal Elastic Anisotropy Index. Phys. Rev. Lett. 2008, 101, 055504. [CrossRef]

56. Touzani, R.S. Quantenchemische Untersuchung der Elastischen und Magnetischen Eigenschaften Einiger Übergangsmetallboride. Ph.D. Thesis, RWTH Aachen University, Aachen, Germany, 2016. (In German)

57. Slater, J.C. Atomic Radii in Crystals. J. Chem. Phys. 1964, 41, 3199-3204. [CrossRef]

58. Touzani, R.S.; Rehorn, C.W.G.; Fokwa, B.P.T. Influence of chemical bonding and mahnetism on elastic properties of the $\mathrm{A}_{2} \mathrm{MB}_{2}$ borides $(\mathrm{A}=\mathrm{Nb}$, Ta; $\mathrm{M}=\mathrm{Fe}, \mathrm{Ru}, \mathrm{Os})$ from first-principles calculations. Comput. Mater. Sci. 2015, 104, 52-59. [CrossRef]

(C) 2020 by the authors. Licensee MDPI, Basel, Switzerland. This article is an open access article distributed under the terms and conditions of the Creative Commons Attribution (CC BY) license (http://creativecommons.org/licenses/by/4.0/). 